\title{
Evaluation of stability and in vitro wound healing potential of melatonin loaded (lipid enriched) chitosan based microspheres
}

\author{
MARIETA DUVNJAK ROMIĆ1 \\ ANJA SUŠAC ${ }^{2}$ \\ JASMINA LOVRIĆ ${ }^{2}$ \\ BISERKA CETINA-ČIŽMEK ${ }^{1}$ \\ JELENA FILIPOVIĆ-GRČIĆ ${ }^{2}$ \\ ANITA HAFNER ${ }^{2, *}$ \\ ${ }^{1}$ RED, PLIVA Croatia Ltd, TEVA Group \\ Member, Zagreb, Croatia \\ ${ }^{2}$ University of Zagreb Faculty of \\ Pharmacy and Biochemistry, Department \\ of Pharmaceutical Technology, Zagreb \\ Croatia
}

\begin{abstract}
The aim of this study was to evaluate long-term stability and assess the wound healing potential of the innovative melatonin-loaded lipid-enriched hybrid system compared to conventional melatonin-loaded chitosan microspheres. The hybrid system contained nanostructured lipid carrier incorporated in the chitosan matrix, in order to modify melatonin release and alter physicochemical characteristics of the delivery system. Stability testing was performed during a six-month period under two conditions: refrigerated $\left(5 \pm 3^{\circ} \mathrm{C}\right)$ and at room temperature $\left(25 \pm 2{ }^{\circ} \mathrm{C} / 60 \pm 5 \% \mathrm{RH}\right)$. Samples stored at both conditions were analyzed in terms of particle size, zeta potential, moisture content and thermal properties. At the end of testing, drug content was determined in all samples. Dressings wound healing potential was assessed by in vitro scratch test using human skin fibroblast cell line. Although both systems showed good stability characteristics, the addition of lipids in the system has improved its wound healing potential.
\end{abstract}

Keywords: melatonin, nanoparticles, microspheres, chitosan, stability, wound healing

Persisting non-healing wounds represent a massive burden for the worldwide healthcare system, with more than 25 billion USD spent per year in the US only (1). Population aging, high incidence of obesity and diabetes and a large number of burn injuries are recognized as a major cause of increased chronic wound prevalence. Wound healing is a well-coordinated physiological process, governed by different cell types and signals. Generally, healing can be divided into four ordered but overlapping processes of haemostasis, inflammation, proliferation and remodelling (2). In most of the cases, the healing process is interrupted during the inflammation phase. Although the aetiology is highly variable, persistent infection, biofilm formation and reduction of granulation and reepithelialisation are common characteristics associated with non-healing wounds $(3,4)$. High incidence of chronic wounds accompanied by increasing bacterial resistance justifies enlarged interest in the development of nonconventional, more efficient therapies.

\footnotetext{
*Correspondence; e-mail: ahafner@pharma.hr
} 
Melatonin, mainly perceived as the pineal gland hormone, has pleiotropic activities as a neurotransmitter, cytokine, biological-response modifier, anti-inflammatory agent and free-radical scavenger (5). While full melatonin potential as a cutaneous agent still needs to be discovered (6), recent in vitro studies showed a positive impact on corneal and diabetic wound healing models $(7,8)$. Owing to its anti-oxidant and anti-inflammatory properties, melatonin shows potential for application in nonconventional dressings for burn and chronic wound treatment (9).

Among many nano-sized drug delivery systems, nanostructured lipid carriers (NLCs) are highly investigated as wound-healing agents (10). NLCs are nanoparticles composed of a blend of solid and liquid lipids (11), with adequate drug loading capacity and stability (compared to solid lipid nanoparticles), providing controlled drug release and skin hydration effect (12). Even though mainly acting as carriers for growth factors or antimicrobial agents $(12,13)$, it was reported that NLCs themselves can promote wound healing in a rat burn model (14).

Chitosan, a linear amino polysaccharide, is widely used as a wound healing promoter, due to its antibacterial, haemostatic and mucoadhesive properties (15). Chitosan-based dressings in form of gels and films are already present as marketed products, whereas in terms of novel systems, chitosan can be formulated as part of artificial skin, powder formulation or coupled to peptides (16).

Our group has recently verified the idea of combining the above-mentioned components for the development of two drug delivery systems for wound management, prepared by spray drying technology. The first one refers to fine-tuned melatonin-loaded chitosan/ Pluronic $^{\circledR}$ F127 microspheres characterized by small diameter, positive surface charge, efficient melatonin encapsulation and high rate and extent of fluid uptake. Formulated dry powder acted as in situ gel-forming dressing with antimicrobial activity, applicable for highly exuding wounds (17). In order to alter microparticulate dressing properties, the novel lipid-enriched hybrid system was developed, comprising NLCs within the chitosan/ Pluronic ${ }^{\circledR}$ F127 matrix, with melatonin incorporated in both, the NLC and chitosan matrix. Influence of formulation and process parameters, on characteristics of prepared lipid and hybrid systems, was evaluated using Design of Experiments approach. The optimized hybrid system showed prolonged melatonin release and good flowability properties while maintaining antimicrobial activity. Reduced swelling and water retaining characteristics made it suitable for application to moderate exuding wounds (18). Both systems were shown to be biocompatible with skin keratinocytes and fibroblasts $(17,18)$.

The aim of this study was to evaluate and compare aforementioned (NLC free and NLC enriched, in the further text indicated as MCP and MLCP) melatonin delivery systems in terms of long-term stability and in vitro wound healing potential.

There are some literature reports on the stability of spray-dried chitosan-based powders $(19,20)$. However, although the conversion of lipid particles to dry powder via spray drying has been evaluated by other researchers $(21,22)$, stability assessment of the lipid component and the dry powder over time is scarce (23). Stability testing was performed during a six-month period under two conditions: refrigerated $\left(5 \pm 3^{\circ} \mathrm{C}\right)$ and at room temperature $\left(25 \pm 2{ }^{\circ} \mathrm{C} / 60 \pm 5 \% \mathrm{RH}\right)$. Samples stored at both conditions were analysed in terms of particle size, zeta potential, moisture content and thermal properties. At the end of the testing, drug content was determined in all samples.

Dressings wound healing potential was assessed by completion of in vitro scratch test using human skin fibroblast cell line. In vitro scratch assay is a widely used conventional 
assay that provides insight about formulation influence on cell migration and proliferation (24). As fibroblasts play a major role in the healing process during inflammation and remodelling phase (25), they were used for the evaluation of developed microsphere-based dressings.

\section{EXPERMENTAL}

\section{Materials}

Compritol ${ }^{\circledR} 888$ ATO (glycerol dibehenate) was a kind gift from Gattefosse (France). Melatonin (China) and chitosan ( $\geq 75 \%$ deacetylated powder, Japan) were purchased from Sigma-Aldrich. Pluronic ${ }^{\circledR}$ F127 was obtained from BASF (Germany). Miglyol ${ }^{\circledR}$ 812N was obtained from Sasol (Germany). All other chemicals and solvents used in the study were of analytical grade and procured from Kemika (Croatia) or Sigma-Aldrich.

\section{Preparation of melatonin loaded chitosan/Pluronic ${ }^{\circledR}$ F127 microspheres}

Melatonin loaded chitosan/Pluronic ${ }^{\circledR}$ F127 microspheres (MCP; i.e. NLC free microspheres) were prepared by spray drying method as previously described (17). Briefly, spray drying feed was prepared by mixing (i) solution of chitosan $\left(10 \mathrm{~g} \mathrm{~L}^{-1}\right)$ in $0.5 \%$ acetic acid solution with (ii) melatonin and Pluronic ${ }^{\circledR}$ F127 solution prepared in $96 \%$ ethanol. Solutions were mixed at a volume ratio of $4 / 1$, respectively, resulting in the spray drying feed with chitosan to melatonin ratio of 2/1 (Table I) and chitosan to Pluronic ${ }^{\circledR}$ F127 ratio of 5/1 (Table I). Spray drying was performed using a Mini Spray Dryer Büchi 190 (Flawil, Switzerland) with an inlet temperature of $145^{\circ} \mathrm{C}$, feed flow rate of $2.59 \mathrm{~mL} \mathrm{~min}^{-1}$, a standard $0.7 \mathrm{~mm}$ nozzle and compressed air flow rate of $700 \mathrm{NL} \mathrm{h}^{-1}$.

\section{Preparation of melatonin loaded NLC enriched chitosan/Pluronic ${ }^{\circledR}$ F127 microspheres}

Preparation of NLCs: Melatonin loaded NLCs were prepared by hot ultrasonication method optimized by our group (18). Briefly, melatonin was dissolved in a Compritol ${ }^{\circledR} 888$ ATO/Miglyol ${ }^{\circledR} 812 \mathrm{~N}$ mixture heated to $90{ }^{\circ} \mathrm{C}$, at melatonin to lipid weight ratio of $2 / 5$ (Table I). The aqueous phase containing Pluronic ${ }^{\circledR}$ F127 was heated to the same temperature and added dropwise to the lipid phase under magnetic stirring. The mass ratio of Pluronic ${ }^{\circledR}$ F127 to dispersed lipids in the obtained pre-emulsion was $1 / 3$. Pre-emulsion was then

Table I. Composition of melatonin-loaded NLC free (MCP) and NLC enriched (MLCP) microspheres

\begin{tabular}{lcccc}
\hline \multirow{2}{*}{ Component } & \multicolumn{2}{c}{ MCP } & \multicolumn{2}{c}{ MLCP } \\
\cline { 2 - 5 } & $\begin{array}{c}\text { Amount } \\
(\%)\end{array}$ & $\begin{array}{c}\text { Mass ratio } \\
\text { to chitosan }\end{array}$ & $\begin{array}{c}\text { Amount } \\
(\%)\end{array}$ & $\begin{array}{c}\text { Mass ratio } \\
\text { to chitosan }\end{array}$ \\
\hline Chitosan & 58.8 & - & 46.1 & - \\
Lipids content in the microspheres & - & - & 21.6 & $2.3 / 5$ \\
Pluronic ${ }^{\circledR}$ F127 & 11.8 & $1 / 5$ & 9.2 & $1 / 5$ \\
Melatonin content in the microspheres & 29.4 & $1 / 2$ & 23.1 & $1 / 2$ \\
\hline
\end{tabular}


M. Duvnjak Romić et al.: Evaluation of stability and in vitro wound healing potential of melatonin loaded (lipid enriched) chitosan based microspheres, Acta Pharm. 69 (2019) 635-648.

subjected to probe sonication (UP200Ht Hielscher, Germany) and melatonin loaded NLCs were formed after cooling down to room temperature.

Preparation of microspheres. - As described in our previous work (18), spray-drying feed for the preparation of melatonin loaded NLC enriched microspheres (MLCP) was prepared by dropwise addition of dispersion of melatonin loaded NLCs to chitosan/melatonin/ Pluronic ${ }^{\circledR}$ F127 solution prepared as for above-mentioned NLC free microspheres. The volume ratio of NLC dispersion to chitosan/melatonin/Pluronic ${ }^{\circledR}$ F127 solution was set to ensure lipid to chitosan mass ratio of 2.3/5 (Table I). Spray drying was performed using a ProCept 4M8-TriX Spray Dryer, with an inlet temperature of $110{ }^{\circ} \mathrm{C}$, feed flow rate of 1.8

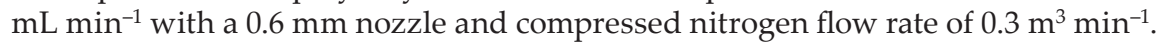

\section{Physico-chemical characteristics of melatonin loaded (NLC enriched) microsphere}

Particle size. - NLC free microspheres (MCP) size and distribution were determined by microscopic imaging analysis technique, using Olympus $\mathrm{BH}-2$ microscope, equipped with a camera (CCD Camera ICD-42E; Ikegami Tsushinki Co., Tokyo, Japan) and computer-controlled image analysis system (Optomax V, Cambridge, UK), with at least 3000 particles examined. NLC enriched microsphere (MLCP) size and distribution were evaluated using a Malvern Morphology G3-ID (Malvern Instruments, UK) with a minimum of 10000 particles examined.

Zeta potential. - The zeta potential of the microspheres was determined by laser Doppler anemometry (Zetasizer $3000 \mathrm{HS}$, Malvern Instruments, UK) at $25^{\circ} \mathrm{C}$, as described in our previous work (17). Briefly, microspheres were dispersed in $10 \mathrm{mM} \mathrm{NaCl}$. Measurement was performed in an electrophoretic cell under the potential of $150 \mathrm{mV}$. Conversion of the measured electrophoretic mobility to zeta potential using the Helmholtz-Smoluchowski equation was performed within the system software.

Drug loading. - The content of melatonin within the microspheres was determined by the HPLC assay method as described previously (18). In short, dispersion of microspheres in $1 \mathrm{~mol} \mathrm{~L}^{-1} \mathrm{HCl} /$ acetonitrile mixture $(1 / 1, V / V)$ was first sonicated, then filtered and diluted with the mixture of $96 \%$ ethanol and purified water $(1 / 4, V / V)$.

An HPLC analysis was performed on Agilent 1100 Series instrument (Agilent Technologies, Germany) equipped with a diode array detector set at $224 \mathrm{~nm}$. The mobile phase contained HPLC grade water and acetonitrile in the ratio of 52/48, The column (Kinetex C18 column $50 \times 4.6 \mathrm{~mm}^{2}$, particle size $5 \mathrm{~mm}$, Phenomenex, USA) suited with an in-line filter (KrudKatcher Ultra HPLC, $0.5 \mu \mathrm{m}$ Depth Filter $\times 0.004$ in, Phenomenex, USA) was used. The analysis was performed under chromatographic conditions as follows: sample injection volume of $10 \mu \mathrm{L}$, isocratic elution, the run time of $1 \mathrm{~min}$, the flow rate of $1 \mathrm{~mL} \mathrm{~min}{ }^{-1}$ and the column temperature of $30^{\circ} \mathrm{C}$.

Thermal analyses. - Modulated differential scanning calorimetry (MDSC) analyses were performed using a TA Instrument modulated DSC Q2000 (TA Instruments, USA). Quantity of about $0.5-1.0 \mathrm{mg}$ of the powder sample was weighed in aluminium standard pans. The analysis was performed under dynamic nitrogen atmosphere at the flow rate of $50 \mathrm{~mL} \mathrm{~min}^{-1}$. Samples were scanned at the heating rate of $5{ }^{\circ} \mathrm{C} \mathrm{min}^{-1}$ from 20 to $220^{\circ} \mathrm{C}$, with modulation of $\pm 1^{\circ} \mathrm{C}$ (amplitude) each $60 \mathrm{~s}$ (period). 
TGA Q5000 (TA Instruments, USA) was used to determine the moisture content in the microsphere samples. Thermogravimetric analysis was performed on the microsphere sample (about $5 \mathrm{mg}$ ) under dynamic nitrogen atmosphere at a flow rate of $35 \mathrm{~mL} \mathrm{~min}^{-1}$. The samples were analysed at the heating rate of $10{ }^{\circ} \mathrm{C} \mathrm{min}^{-1}$ in the temperature range of 25 to $500{ }^{\circ} \mathrm{C}$.

Stability testing scheme. - Stability testing was performed during a six-month period. Sample containers were sealed, protected from light and kept refrigerated $\left(5 \pm 3^{\circ} \mathrm{C}\right)$ and at room conditions $\left(25 \pm 2{ }^{\circ} \mathrm{C} / 60 \pm 5 \% \mathrm{RH}\right)$. Samples stored at both conditions were analysed in terms of particle size, zeta potential, moisture content and thermal properties. At the end of testing, drug content was determined in all samples.

\section{In vitro scratch assay}

In vitro scratch assay was performed using Human diploid fibroblast strain MJ90hTERT (kindly provided by Dr. Ivica Rubelj, Institute Ruđer Bošković, Zagreb, Croatia) (26), cultured in DMEM medium (GIBCO, UK) under supplementation with $10 \%$ foetal bovine serum (FBS, GIBCO) and antimicrobial solution (Sigma-Aldrich).

MJ90hTERT cells were seeded onto 24-well plates and allowed to reach confluence over 1 day in DMEM medium supplemented with $10 \%$ FBS. Subsequently, medium was removed and replaced with serum-free medium. Next day ( $24 \mathrm{~h}$ later) a straight scratch was made with a $100 \mu \mathrm{L}$ pipette tip, to simulate a wound (27). The cell monolayer was washed with HBSS (pH 7.4) to remove detached cells and cell debris. The wound was exposed to MCP and MLCP suspensions, in HBSS pH 7.4 and 6.3, at melatonin concentration of $0.3 \mathrm{mg} \mathrm{mL}^{-1}$ and corresponding chitosan concentration of $0.6 \mathrm{mg} \mathrm{mL}^{-1}$, that were set based on our previous studies. Namely, MCP and NLCP systems were shown to exhibit antimicrobial effect and fibroblast cell line compatibility at selected melatonin and chitosan concentrations $(17,18)$. Non-treated cells incubated in HBSS ( $\mathrm{pH} 7.4$ or 6.3) served as control. After the 2-hour treatment, cells were washed with HBSS pH 7.4 and incubated with serum-free medium. The closure of the scratch (in vitro wound healing) was monitored over $24 \mathrm{~h}$ using an inverted microscope ( $5 \times$ magnification; Olympus CKX41) equipped with a camera (Samsung, $16 \mathrm{MP}, \mathrm{f} / 1.9$ ). To measure the rate of scratch closure, the difference between wound area at time 0 and after $24 \mathrm{~h}$ was determined. Each well was marked below the plate surface by drawing a vertical line, to enable exploration and evaluation of the same scratched zone. Scratch area was estimated using ImageJ software (National Institutes of Health, USA). Wound healing rate (WHR) was expressed as a percentage of the scratch closure on an initial area basis, according to the following equation:

$$
W H R=\frac{A_{0}-A_{24}}{A_{0}} \times 100
$$

where $A_{0}$ is the scratch area at time 0 , and $A_{24}$ is the corresponding scratch area at $24 \mathrm{~h}$. The values shown are the means of three wells from three independent experiments.

\section{Statistical analysis}

Statistical data analyses were performed on all in vitro data by one-way analysis of variance (ANOVA) followed by multiparametric Tukey's post hoc test with $p<0.05$ as the minimal level of significance. Calculations were performed using GraphPad Prism software (GraphPad Software, Inc., USA). 


\section{RESULTS AND DISCUSSION}

\section{Physico-chemical characteristics of melatonin loaded (NLC enriched) microspheres}

NLC free an NLC enriched microspheres were successfully prepared by spray drying method. Main characteristics of the microspheres (mean diameter, zeta potential and moisture content) are reported in Table II.

Mean diameter of MLCP was higher than the mean diameter of MCP (3.3 vs. $2.7 \mu \mathrm{m}$, Table II). During the six-month storage at both conditions $\left(5^{\circ} \mathrm{C}\right.$ and $25{ }^{\circ} \mathrm{C} / 60 \% \mathrm{RH}$ ), no significant changes in particle size for both samples were observed. This is in agreement with the literature report on accelerated stability studies of chitosan-based spray dried microspheres conducted at $40 \pm 2{ }^{\circ} \mathrm{C}$ and $75 \pm 5 \%$ RH for a period of 3 months (28).

Both types of microspheres were initially characterised with positive surface charge due to the presence of chitosan at the microsphere surface, with lower values for MLCP due to the presence of negatively charged lipids in the system. Although slight changes in zeta potential during storage were observed for both samples, the decrease was shown not to be significant (Table II).

MCP had lower initial moisture content compared to MLCP (Table II), which could be explained by higher inlet temperature employed $\left(145^{\circ} \mathrm{C}\right.$ vs. $110{ }^{\circ} \mathrm{C}$, respectively) during spray drying. Higher inlet temperature resulted in higher outlet temperature and consequent lower moisture content of the MCP microspheres at the end of the drying process (21). However, upon storage, moisture content of MCP increased by $\sim 20 \%$ for samples kept at $5{ }^{\circ} \mathrm{C}$ and by $\sim 40 \%$ for samples kept at $25{ }^{\circ} \mathrm{C} / 60 \% \mathrm{RH}$. No change in the moisture content

Table II. Characteristics of melatonin-loaded NLC free microspheres (MCP) and melatonin-loaded NLC enriched microspheres $(M L C P)$ during stability testing ${ }^{a}$

\begin{tabular}{ccccccc}
\hline \multirow{2}{*}{ Time (month) } & \multicolumn{2}{c}{ Mean diameter $(\mu \mathrm{m})$} & \multicolumn{2}{c}{ Zeta potential $(\mathrm{mV})$} & \multicolumn{2}{c}{ Moisture content $(\%)$} \\
\cline { 2 - 7 } & MCP & MLCP & MCP & MLCP & MCP & MLCP \\
\hline start & $2.7 \pm 0.3$ & $3.3 \pm 0.2^{\mathrm{b}}$ & $29.0 \pm 2.0$ & $26.6 \pm 0.5^{\mathrm{b}}$ & $2.5 \pm 0.1$ & $4.7 \pm 0.1^{\mathrm{b}}$ \\
\hline 1 & $2.7 \pm 0.9$ & $3.2 \pm 0.4$ & $25.3 \pm 1.0$ & $26.1 \pm 0.5$ & $3.0 \pm 0.1$ & $4.4 \pm 0.1$ \\
2 & $2.6 \pm 0.4$ & $3.0 \pm 0.2$ & $29.9 \pm 0.8$ & $26.4 \pm 0.9$ & $3.0 \pm 0.1$ & $4.4 \pm 0.2$ \\
3 & $2.6 \pm 0.1$ & $3.1 \pm 0.3$ & $26.8 \pm 2.8$ & $25.7 \pm 1.1$ & $2.9 \pm 0.2$ & $4.5 \pm 0.1$ \\
6 & $2.6 \pm 0.5$ & $3.2 \pm 0.5$ & $25.9 \pm 3.8$ & $25.3 \pm 1.0$ & $3.1 \pm 0.3$ & $4.5 \pm 0.1$ \\
\hline 1 & & & Stored at ${ }^{\circ} \mathrm{C}$ & \\
\hline 2 & $2.8 \pm 0.0$ & $3.3 \pm 0.3$ & $23.0 \pm 0.5$ & $25.9 \pm 0.7$ & $3.4 \pm 0.1$ & $4.5 \pm 0.2$ \\
6 & $2.4 \pm 0.8$ & $3.4 \pm 0.4$ & $24.6 \pm 1.1$ & $26.0 \pm 0.4$ & $3.6 \pm 0.6$ & $4.6 \pm 0.2$ \\
\hline 6 & $2.5 \pm 0.8$ & $3.2 \pm 0.3$ & $24.6 \pm 1.8$ & $25.4 \pm 0.5$ & $3.5 \pm 0.1$ & $4.5 \pm 0.0$ \\
\hline
\end{tabular}

\footnotetext{
a mean values $\pm \mathrm{SD}, n=3$
}

${ }^{\mathrm{b}}$ Characterization results at the start of testing for MLCP have already been reported by Duvnjak Romić et al. (18). 
for MLCP microspheres was observed, regardless of the storage conditions employed. It is well known that chitosan's positively charged amino groups are prone to capture water (29). Lower water sorption of MLCP microspheres in comparison to MCP microspheres might be explained by the interaction between positively charged chitosan and negatively charged lipids acting as matrix stabilizing agents. Although ionic interactions between components were not previously detected, weak ionic associations that manifest as lower positive zeta potential in case of MLCP microspheres could be present (18).

It is known that melatonin is susceptible to degradation on exposure to air and light (30), while when formulated in dosage form, its stability is improved (31). Thus, melatonin content in microspheres was determined after six-month storage. In the case of MCP sample, no changes in melatonin content were observed. Samples stored refrigerated and at room temperature contained more than $97 \%$ of the melatonin at the end of the testing period. The MLCP microspheres showed a slight decrease in content, with $93 \%$ melatonin remaining in the MLCP microspheres after 6 months at $5{ }^{\circ} \mathrm{C}$ and $91 \%$ under room conditions.

\section{Thermal characteristics of melatonin loaded NLC free and NLC enriched microspheres}

Thermal analyses of microspheres were employed in order to determine and monitor components' behaviour and interactions during storage. Crystalline melatonin is characterized by an endothermic peak (melting point, $T_{\mathrm{m}}$ ) appearing at midpoint temperature of

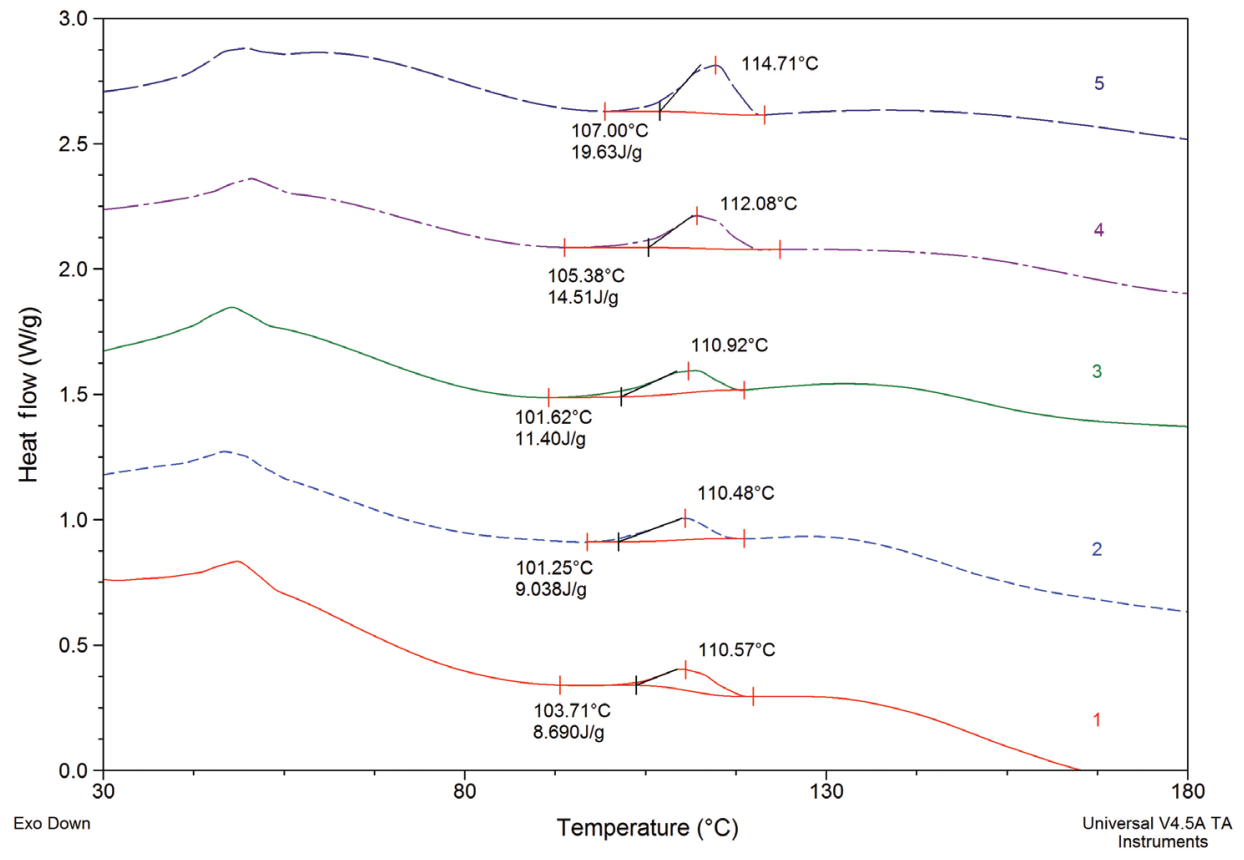

Fig. 1. DSC thermographs of melatonin loaded microspheres (MCP) immediately after the preparation (1), and after one (2), two (3), three (4) and six months (5) at $5 \pm 3{ }^{\circ} \mathrm{C}$. 
$117.88^{\circ} \mathrm{C}$ with the heat of fusion of $140.2 \mathrm{~J} \mathrm{~g}^{-1}$ (17). Melatonin melting point in MCP immediately upon the preparation is detected at $110.57^{\circ} \mathrm{C}$ (Fig. 1 and 2), which indicates an interaction of the drug with polymers (chitosan and lipids). The decrease in heat of fusion of melatonin in microspheres indicates the occurrence of partially amorphous melatonin due to the spray drying process (17). Therefore, midpoint temperature and heat of fusion were used as indicators of the melatonin state in the MCP during storage. In the Fig. 1 it can be seen that throughout the storage time at $5^{\circ} \mathrm{C}, T_{\mathrm{m}}$ and heat of fusion values increase, as a sign of the progressive transformation of amorphous melatonin to the crystalline state.

Fig. 2 presents the thermographs of the MCP throughout storage at $25{ }^{\circ} \mathrm{C} / 60 \% \mathrm{RH}$. Although the shift of melting point towards higher temperature is observed, the heat of fusion does not change significantly over time indicating improved stability of the MCP at a higher temperature. As microspheres contain a moderate amount of moisture, Pluronic ${ }^{\circledR}$ F127 could easily be dissolved at low temperatures (32). This effect could lead to the dissolution of amorphous melatonin and consequent precipitation as crystalline material when the temperature increases. The above hypothesis could explain improved MCP stability when stored at room temperature.

Thermographs of MLCP samples were characterized by an additional endothermic peak attributed to the melting point $\left(T_{\mathrm{m}}\right)$ of solid lipid Compritol ${ }^{\circledR} 888$ ATO (Figs. 3 and 4 ). Compared to pure Compritol ${ }^{\circledR} 888$ ATO that has $T_{\mathrm{m}}$ at $70.3^{\circ} \mathrm{C}(18)$, the shift of the melting point towards lower temperature was observed in MLCPs. When formulated in NLCs, solid lipids are organised in less ordered structures, thus promoting the inclusion of drug

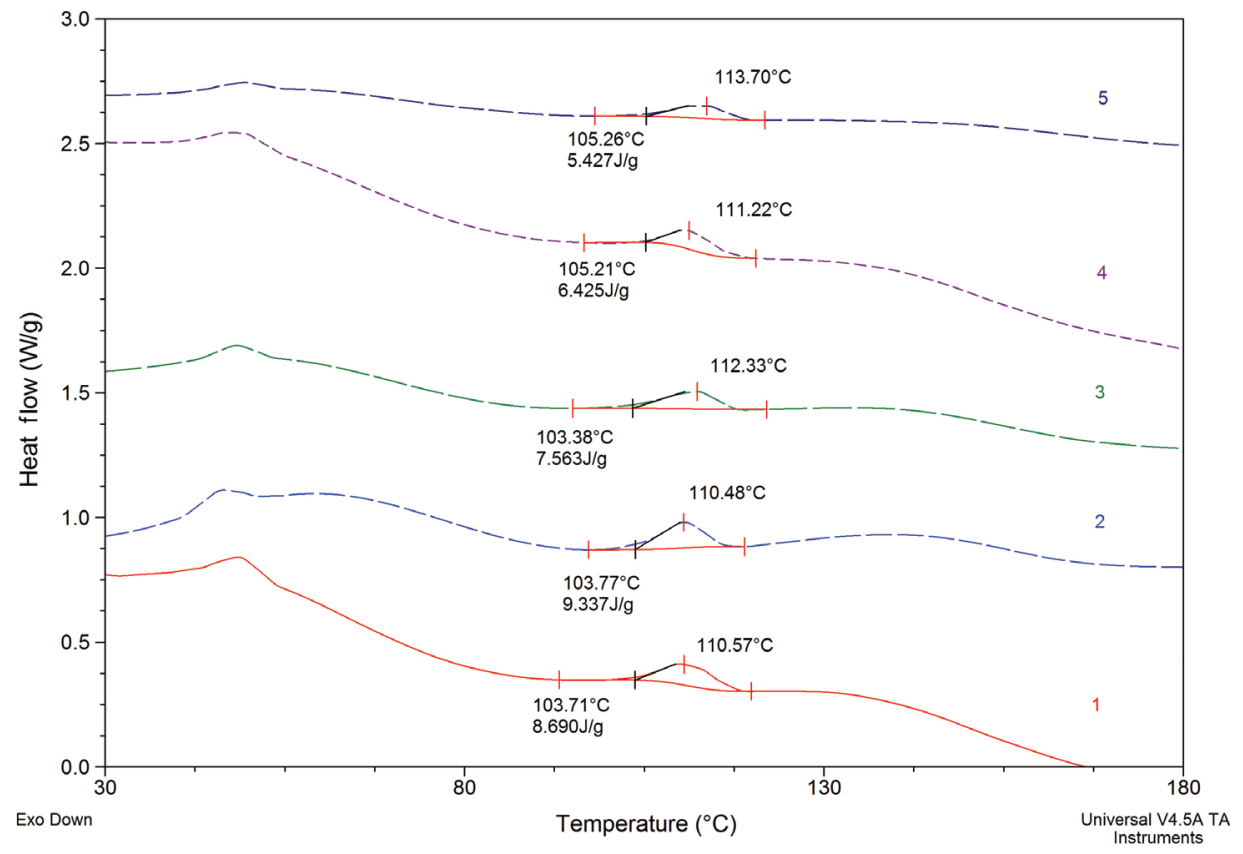

Fig. 2. DSC thermographs of melatonin loaded microspheres (MCP) immediately after the preparation (1) and after one (2), two (3), three (4) and six months (5) at $25^{\circ} \mathrm{C} / 60 \% \mathrm{RH}$. 
M. Duvnjak Romić et al.: Evaluation of stability and in vitro wound healing potential of melatonin loaded (lipid enriched) chitosan based microspheres, Acta Pharm. 69 (2019) 635-648.

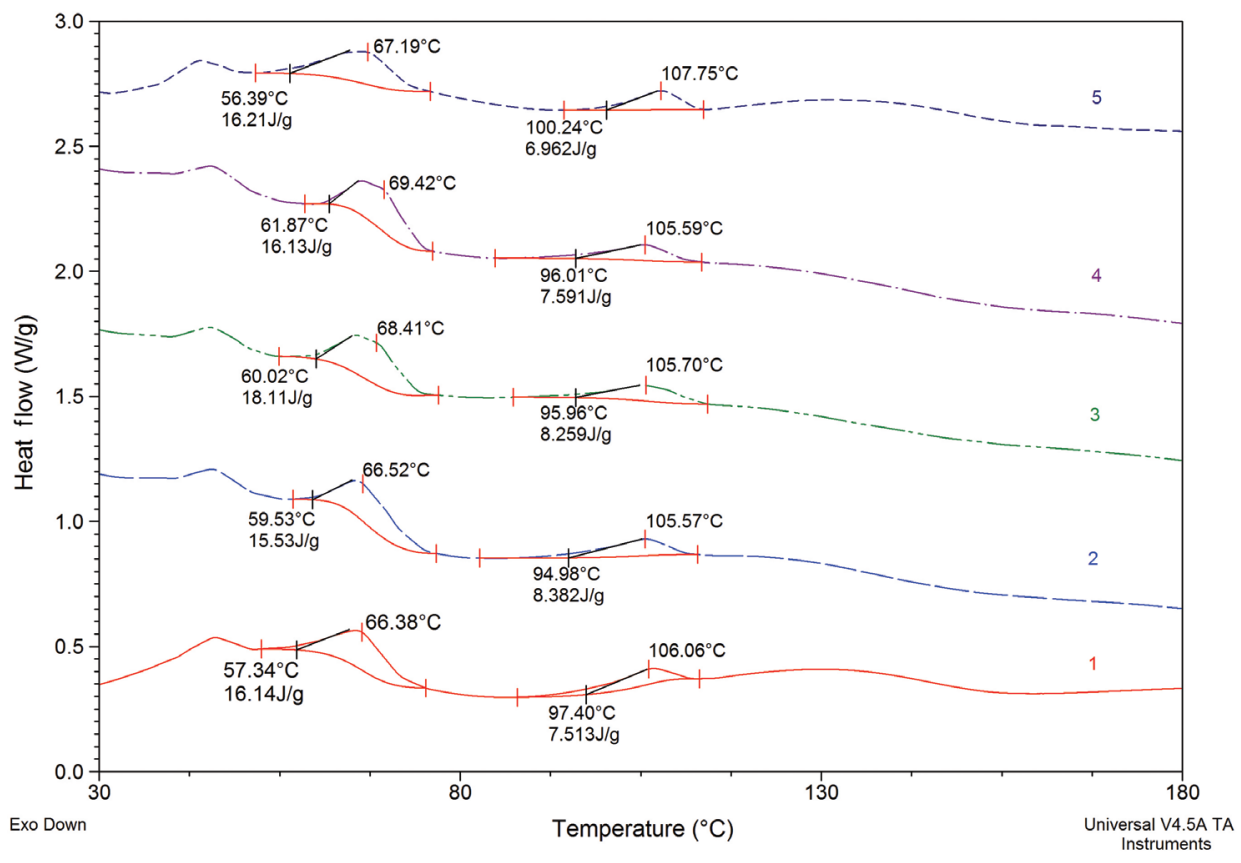

Fig. 3. DSC thermographs of melatonin loaded NLC enriched microspheres (MLCP) immediately after the preparation (1) and after one (2), two (3), three (4) and six months (5) at $5 \pm 3{ }^{\circ} \mathrm{C}$.

molecules and enhancing drug stability (33). Therefore, the shift in $T_{\mathrm{m}}$ for Compritol ${ }^{\circledR} 888$ ATO demonstrates the presence of NLCs within the microspheres. Considering the latter, $T_{\mathrm{m}}$ and heat of fusion for both, melatonin and Compritol ${ }^{\circledR} 888$ ATO were evaluated during MLCP stability study.

Fig. 3 represents thermographs of MLCP samples stored for 6 months at $5{ }^{\circ} \mathrm{C}$. It was observed that no significant changes in $T_{\mathrm{m}}$ or heat of fusion for both melatonin and Compritol $^{\circledR} 888$ ATO occurred. Results indicate that after six months there was no change in the crystalline state of melatonin and that lipids still existed in the form of NLCs within the microspheres.

When stored at room temperature (Fig. 4), change in the state of $\mathrm{Compritol}^{\circledR} 888$ ATO to the most stable form occurred, which is indicated with an increase in $T_{\mathrm{m}}$ and the heat of fusion. At the same time, there was no significant change in $T_{\mathrm{m}}$ and heat of fusion related to melatonin. Observed data showed that decomposition of NLC within microspheres progressed with time at $25^{\circ} \mathrm{C} / 60 \% \mathrm{RH}$, while there was no significant change in melatonin state or content.

\section{In vitro scratch wound healing assay}

In vitro scratch wound healing assay was carried out to evaluate the effect of developed MCP and MLCP microspheres on fibroblast migration/proliferation and consequent wound repair potential. Microspheres were dispersed in HBSS buffer set to physiologically 
M. Duvnjak Romić et al.: Evaluation of stability and in vitro wound healing potential of melatonin loaded (lipid enriched) chitosan based microspheres, Acta Pharm. 69 (2019) 635-648.

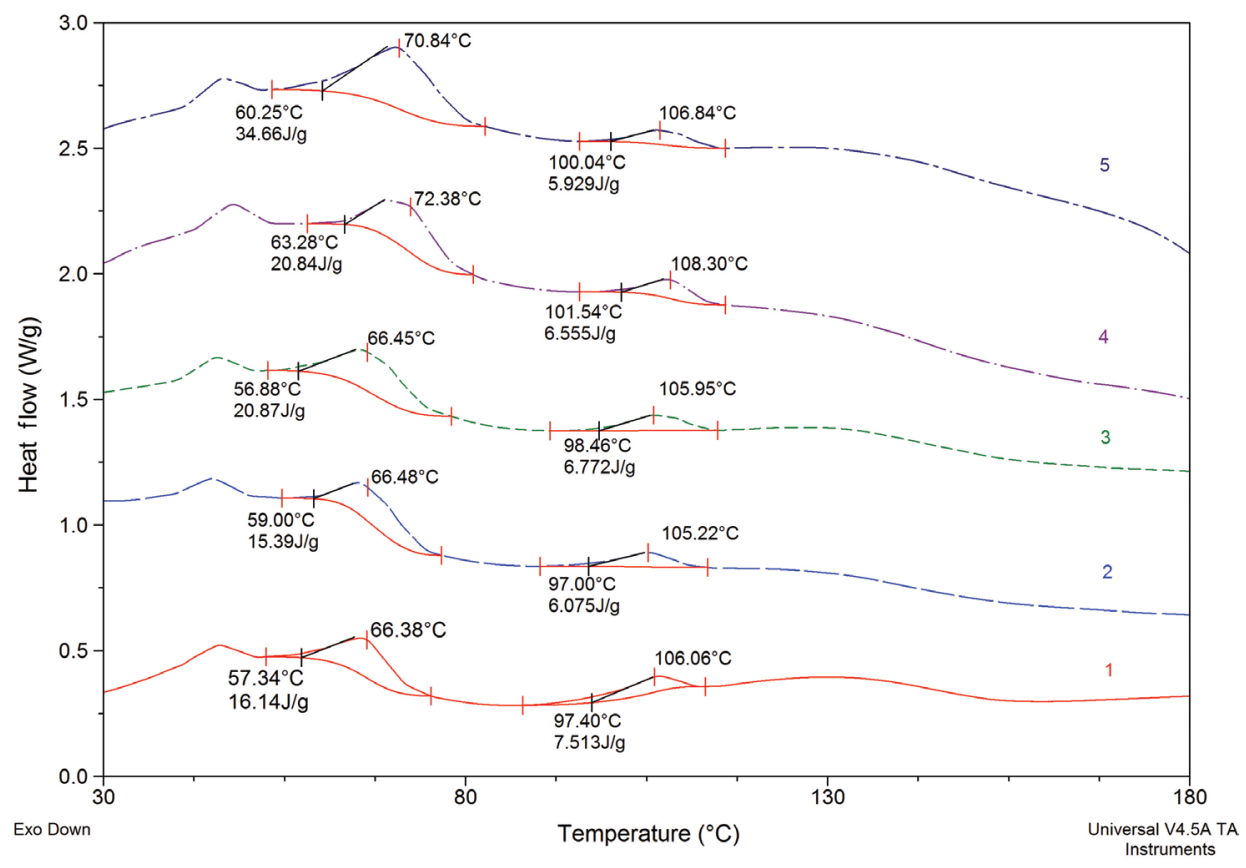

Fig. 4. DSC thermographs of melatonin loaded NLC enriched microspheres (MLCP) immediately after the preparation (1) and after one (2), two (3), three (4) and six months (5) at $25^{\circ} \mathrm{C} / 60 \% \mathrm{RH}$.

relevant $\mathrm{pH} 7.4$ and $\mathrm{pH}$ 6.3, that has been measured in the bacterial broth (17). Although it was postulated that an increase in wound bed $\mathrm{pH}$ indicates contamination and interruption in healing (35), lower micro-environmental $\mathrm{pH}$ milieu is expected for saccharolytic

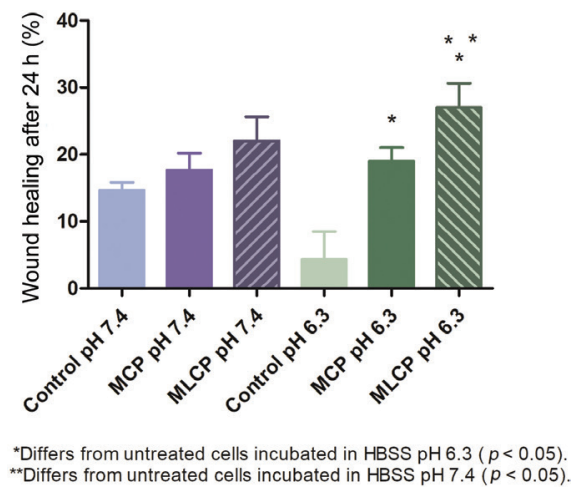

Fig. 5. Influence of melatonin loaded microspheres (MCP) and melatonin loaded NLC enriched microspheres (MLCP) dispersed in HBSS ( $\mathrm{pH} 7.4$ or 6.3) on scratch wound healing (mean values $\pm \mathrm{SD}$, $n=3$ ). The wound closure rate is expressed as the percentage of scratch closure after $24 \mathrm{~h}$ compared to the initial area $(0 \mathrm{~h})$. Controls refer to untreated cells incubated in HBSS medium ( $\mathrm{pH} 7.4$ or 6.3). 
bacterial infections (36). Our group has previously reported biocompatibility of MCP and MLCP systems with human skin cell lines at both $\mathrm{pH}$ levels, namely pH 7.4 and $\mathrm{pH} 6.3$ (17, 18). Results presented in Fig. 5 reveal that MPC and MLPC accelerated wound healing when compared to the control in the 24 -h period after cell treatment. These results indicate that developed systems retained the healing potential of the main components reported previously by other researchers $(27,37-39)$.

Although improvement in wound healing rate after treatment at $\mathrm{pH} 7.4$ was observed, it was not found significant. However, major improvement of scratch closure was obtained at $\mathrm{pH}$ 6.3, indicating the beneficial effect of partially solubilized chitosan in slightly acidic conditions. Proliferation/migration of untreated fibroblasts incubated in HBSS at pH 6.3 (Control pH 6.3; Fig. 5) was the lowest among all the tested variants. Due to the simplicity of the scratch assay, replicating only a limited segment of the tissue structure and function of the wound bed, higher susceptibility of cell monolayer to non-physiological $\mathrm{pH}$ is anticipated. Therefore, healing of model wounds treated with microsphere suspensions in HBSS at pH 6.3 (MCP pH 6.3 and MLCP pH 6.3, Fig. 5) was also evaluated in comparison to the untreated model wound incubated in HBSS at pH 7.4 (Control pH 7.4; Fig. 5). Even in that case, the improved closure of wound treated with MLCP was found significant. More prominent wound closure for cells treated with MLCP in relation to MCP signifies the beneficial effect of lipids in the system. A similar concept where NLCs acted as an accompanying healing factor in the wound dressing was recently proposed and confirmed by other researchers $(40,41)$.

\section{CONCLUSIONS}

In this study, long term stability of NLC enriched and NLC free microspheres was assessed at refrigerated $\left(5 \pm 3{ }^{\circ} \mathrm{C}\right)$ and room temperature $\left(25 \pm 2{ }^{\circ} \mathrm{C} / 60 \pm 5 \% \mathrm{RH}\right)$ over a six-month period. Both systems showed good stability in general, with NLC free microspheres favouring storage at room temperature due to better preservation of amorphous melatonin. Oppositely, the lower temperature is the condition of choice for long term storage in case of NLC enriched microspheres, as a result of improved conservation of lipid nanosystem. In vitro scratch wound healing assay showed the respectable potential of developed systems for application as a functional wound dressing.

Acknowledgments. - This research was supported by PLIVA Croatia Ltd, TEVA Group Member, as part of the project "Melatonin-loaded chitosan (nano)systems".

\section{REFERENCES}

1. R. G. Frykberg and J. Banks, Challenges in the treatment of chronic wounds, Adv. Wound Care 4 (2015) 560-582; https://doi.org/10.1089/wound.2015.0635

2. T. Shipperley, C. Martin and B. Healthcare, The physiology of wound healing : an emergency response, Surg. 35 (2011) 8-10; http://www.sciencedirect.com/science/article/pii/S0263931917301369

3. K. Kaplani, S. Koutsi, V. Armenis, F. G. Skondra, N. Karantzelis, S. Champeris Tsaniras and S. Taraviras, Wound healing related agents: Ongoing research and perspectives, Adv. Drug Deliv. Rev. (2018); https://doi.org/10.1016/j.addr.2018.02.007 
M. Duvnjak Romić et al.: Evaluation of stability and in vitro wound healing potential of melatonin loaded (lipid enriched) chitosan based microspheres, Acta Pharm. 69 (2019) 635-648.

4. Y.-K. Wu, N.-C. Cheng and C.-M. Cheng, Biofilms in chronic wounds: pathogenesis and diagnosis, Trends Biotechnol. 37 (2019) 505-517; https://doi.org/10.1016/j.tibtech.2018.10.011

5. R. J. Reiter, D.-X. Tan, L. Fuentes-Broto and M. Luciano, Chapter 8 - Melatonin: A multitasking molecule, Progress in Brain Res. 181 (2010) 127-151; https://doi.org/10.1016/S0079-6123(08)81008-4

6. R. Hardeland, A. T. Slominski, R. M. Slominski, R. J. Reiter, M. A. Zmijewski and R. Paus, Melatonin: A cutaneous perspective on its production, metabolism, and functions, J. Invest. Dermatol. 138 (2018) 490-499; https://doi.org/10.1016/j.jid.2017.10.025

7. A. Crooke, A. Guzman-Aranguez, A. Mediero, P. Alarma-Estrany, G. Carracedo, T. Pelaez, A. Peral and J. Pintor, Effect of melatonin and analogues on corneal wound healing: involvement of $\mathrm{Mt}_{2}$ melatonin receptor, Curr. Eye Res. 40 (2015) 56-65; https://doi.org/10.3109/02713683.2014.914540

8. R. Song, L. Ren, H. Ma, R. Hu, H. Gao, L. Wang, X. Chen, Z. Zhao and J. Liu, Melatonin promotes diabetic wound healing in vitro by regulating keratinocyte activity, Am. J. Transl. Res. 8 (2016) 46824693.

9. R. Murali, P. Thanikaivelan and K. Cheirmadurai, Melatonin in functionalized biomimetic constructs promotes rapid tissue regeneration in Wistar albino rats, J. Mater. Chem. B 4 (2016) 5850; https://doi.org/10.1039/c6tb01221c.

10. I. Garcia-Orue, J. L. Pedraz, R. M. Hernandez and M. Igartua, Nanotechnology-based delivery systems to release growth factors and other endogenous molecules for chronic wound healing, J. Drug Deliv. Sci. Technol. 42 (2017) 2-17; https://doi.org/10.1016/j.jddst.2017.03.002

11. J. Pardeike, A. Hommoss and R. H. Müller, Lipid nanoparticles (SLN, NLC) in cosmetic and pharmaceutical dermal products, Int. J. Pharm. 366 (2009) 170-184; https://doi.org/10.1016/j. ijpharm.2008.10.003

12. G. Gainza, M. Pastor, J. J. Aguirre, S. Villullas, J. L. Pedraz, R. M. Hernandez and M. Igartua, A novel strategy for the treatment of chronic wounds based on the topical administration of rhEGF-loaded lipid nanoparticles: In vitro bioactivity and in vivo effectiveness in healing-impaired $\mathrm{db} / \mathrm{db}$ mice, J. Control. Release 185 (2014) 51-61; https://doi.org/10.1016/j.jconrel.2014.04.032

13. N. Karimi, B. Ghanbarzadeh, H. Hamishehkar, B. Mehramuz and H. S. Kafil, Antioxidant, antimicrobial and physicochemical properties of turmeric extract-loaded nanostructured lipid carrier (NLC), Colloid. Interface Sci. Commun. 22 (2018) 18-24; https://doi.org/10.1016/j.colcom.2017.11.006

14. F. Saporito, G. Sandri, M. C. Bonferoni, S. Rossi, C. Boselli, A. I. Cornaglia, B. Mannucci, P. Grisoli, B. Vigani and F. Ferrari, Essential oil-loaded lipid nanoparticles for wound healing, Int. J. Nanomed. 13 (2018) 175-186; https://doi.org/10.2147/IJN.S152529

15. Z. Ma, A. Garrido-Maestu and K. C. Jeong, Application, mode of action, and in vivo activity of chitosan and its micro- and nanoparticles as antimicrobial agents: A review, Carbohydr. Polym. 176 (2017) 257-265; https://doi.org/10.1016/j.carbpol.2017.08.082

16. V. Patrulea, V. Ostafe, G. Borchard and O. Jordan, Chitosan as a starting material for wound healing applications, Eur. J. Pharm. Biopharm. (2015); https://doi.org/10.1016/j.ejpb.2015.08.004

17. M. Duvnjak Romić, M. Š. Klarić, J. Lovrić, I. Pepić, B. Cetina-Čižmek, J. Filipović-Grčić and A. Hafner, Melatonin-loaded chitosan/Pluronic ${ }^{\circledR}$ F127 microspheres as in situ forming hydrogel: An innovative antimicrobial wound dressing, Eur. J. Pharm. Biopharm. 107 (2016) 67-79; https://doi. org/10.1016/j.ejpb.2016.06.013

18. M. Duvnjak Romić, D. Špoljarić, M. Š. Klarić, B. Cetina-Čižmek, J. Filipović-Grčić and A. Hafner, Melatonin loaded lipid enriched chitosan microspheres - Hybrid dressing for moderate exuding wounds, J. Drug Deliv. Sci. Technol. (2019); https://doi.org/10.1016/j.jddst.2019.05.004

19. B. N. Estevinho, F. Rocha, L. Santos and A. Alves, Microencapsulation with chitosan by spray drying for industry applications - A review, Trends Food Sci. Technol. 31 (2013) 138-155; https://doi. org/10.1016/j.tifs.2013.04.001 
20. B. R. P. Cabral, P. M. de Oliveira, G. M. Gelfuso, T. de S. C. Quintão, J. A. Chaker, M. G. de O. Karnikowski and E. F. Gris, Improving stability of antioxidant compounds from Plinia cauliflora (jabuticaba) fruit peel extract by encapsulation in chitosan microparticles, J. Food Eng. 238 (2018) 195-201; https://doi.org/10.1016/j.jfoodeng.2018.06.004

21. D. P. Gaspar, M. M. Gaspar, C. V. Eleutério, A. Grenha, M. Blanco, L. M. D. Gonçalves, P. Taboada, A. J. Almeida and C. Remunán-López, Microencapsulated solid lipid nanoparticles as a hybrid platform for pulmonary antibiotic delivery, Mol. Pharmaceutics 14 (2017) 2977-2990; https:/doi. org/10.1021/acs.molpharmaceut.7b00169

22. T. Wang, Q. Hu, M. Zhou, J. Xue and Y. Luo, Preparation of ultra-fine powders from polysaccharidecoated solid lipid nanoparticles and nanostructured lipid carriers by innovative nano spray drying technology, Int. J. Pharm. 511 (2016) 219-222; https://doi.org/10.1016/j.ijpharm.2016.07.005

23. H. Salminen, J. Ankenbrand, B. Zeeb, G. Badolato Bönisch, C. Schäfer, R. Kohlus and J. Weiss, Influence of spray drying on the stability of food-grade solid lipid nanoparticles, Food Res. Int. 119 (2018) 741-750; https://doi.org/10.1016/j.foodres.2018.10.056

24. D. G. Sami, H. H. Heiba and A. Abdellatif, Wound healing models: A systematic review of animal and non-animal models, Wound Med. 24 (2019) 8-17; https://doi.org/10.1016/j.wndm.2018.12.001

25. A. Stunova and L. Vistejnova, Dermal fibroblasts - A heterogeneous population with regulatory function in wound healing, Cytokine Growth Factor Rev. 39 (2018) 137-150; https://doi.org/10.1016/j. cytogfr.2018.01.003

26. I. Rubelj, Telomere Q-PNA-FISH - reliable results from stochastic signals, PLoS One 9 (2014) e92559; https://doi.org/10.1371/journal.pone.0092559

27. F. Felice, Y. Zambito, E. Belardinelli, A. Fabiano, T. Santoni and R. Di Stefano, Effect of different chitosan derivatives on in vitro scratch wound assay: A comparative study, Int. J. Biol. Macromol. 76 (2015) 236-241; https://doi.org/10.1016/j.ijbiomac.2015.02.041

28. A. D. Kulkarni, D. B. Bari, S. J. Surana and C. V Pardeshi, In vitro, ex vivo and in vivo performance of chitosan-based spray-dried nasal mucoadhesive microspheres of diltiazem hydrochloride, J. Drug Deliv. Sci. Technol. 31 (2016) 108-117; https://doi.org/10.1016/j.jddst.2015.12.004

29. S. Demarger-Andre and A. Domard, Chitosan carboxylic acid salts in solution and in the solid state, Carbohydr. Polym. 23 (1994) 211-219; https://doi.org/10.1016/0144-8617(94)90104-X

30. N. El Moussaoui and A. Bendriss, The influence of storage conditions on melatonin stability, Int. J. Eng. Res. Technol. 3 (2014) 2243-2246.

31. M. Friciu, T. Savji, S. Zaraa and G. Leclair, Evaluation of stability of melatonin in extemporaneously compounded oral suspensions, J. Pharm. Pract. Res. 46 (2016) 28-33; https://doi.org/10.1002/jppr.1171

32. P. Linse and M. Malmsten, Temperature-dependent micellization in aqueous block copolymer solutions, Macromolecules 25 (1992) 5434-5439; https://doi.org/10.1021/ma00046a048

33. A. Garcês, M. H. Amaral, J. M. Sousa Lobo and A. C. Silva, Formulations based on solid lipid nanoparticles (SLN) and nanostructured lipid carriers (NLC) for cutaneous use: A review, Eur. J. Pharm. Sci. 112 (2018) 159-167; https://doi.org/10.1016/j.ejps.2017.11.023

34. B. M. Dulmovits and I. M. Herman, Microvascular remodeling and wound healing: A role for pericytes, Int. J. Biochem. Cell Biol. 44 (2012) 1800-1812; https://doi.org/10.1016/j.biocel.2012.06.031

35. S. L. Percival, S. McCarty, J. A. Hunt, E. J. Woods, The effects of $\mathrm{pH}$ on wound healing, biofilms, and antimicrobial efficacy, Wound Rep. Reg. 22 (2014) 174-186; https://doi.org/10.1111/wrr.12125

36. D. B. Friedman, D. L. Stauff, G. Pishchany, C. W. Whitwell, V. J. Torres and E. P. Skaar, Staphylococcus aureus redirects central metabolism to increase iron availability, PLoS Pathog. 2 (2006) 0777-0789; https://doi.org/10.1371/journal.ppat.0020087

37. X. Chen, L. H. Peng, Y. H. Shan, N. Li, W. Wei, L. Yu, Q. M. Li, W. Q. Liang and J. Q. Gao, Astragaloside IV-loaded nanoparticle-enriched hydrogel induces wound healing and anti-scar activity through topical delivery, Int. J. Pharm. 447 (2013) 171-181; https://doi.org/10.1016/j.ijpharm.2013.02.054 
38. V. Kant, A. Gopal, D. Kumar, A. Gopalkrishnan, N. N. Pathak, N. P. Kurade, S. K. Tandan and D. Kumar, Topical pluronic F-127 gel application enhances cutaneous wound healing in rats, Acta Histochem. 116 (2014) 5-13; https://doi.org/10.1016/j.acthis.2013.04.010

39. G. Soybir, C. Topuzlu, Ö. Odabaş, K. Dolay, A. Bilir and F. Köksoy, The effects of melatonin on angiogenesis and wound healing, Surg. Today. 33 (2003) 896-901; https://doi.org/10.1007/s00595-0032621-3

40. I. Garcia-Orue, G. Gainza, P. Garcia-Garcia, F. B. Gutierrez, J. J. Aguirre, R. M. Hernandez, A. Delgado and M. Igartua, Composite nanofibrous membranes of PLGA/Aloe vera containing lipid nanoparticles for wound dressing applications, Int. J. Pharm. (2019); https://doi.org/10.1016/j.ijpharm.2018.12.010.

41. M. Ghodrati, M. R. Farahpour and H. Hamishehkar, Encapsulation of Peppermint essential oil in nanostructured lipid carriers: In-vitro antibacterial activity and accelerative effect on infected wound healing, Colloids Surfaces A Physicochem. Eng. Asp. (2019); https://doi.org/10.1016/j.colsurfa.2018.12.043 